\title{
BMJ Open Gastrostomy uptake in motor neurone disease: a mixed-methods study of patients' decision making
}

\author{
Julie Labra (D) , ${ }^{1}$ Anne Hogden (10 , ${ }^{2}$ Emma Power, ${ }^{3}$ Natalie James, ${ }^{4}$ \\ Victoria M Flood ${ }^{5,6}$
}

To cite: Labra J, Hogden A, Power E, et al. Gastrostomy uptake in motor neurone disease: a mixed-methods study of patients' decision making. BMJ Open 2020;10:e034751. doi:10.1136/ bmjopen-2019-034751

- Prepublication history and additional material for this paper are available online. To view these files, please visit the journal online (http://dx.doi. org/10.1136/bmjopen-2019034751).

Received 04 October 2019 Revised 24 December 2019 Accepted 09 January 2020

Check for updates

(C) Author(s) (or their employer(s)) 2020. Re-use permitted under CC BY-NC. No commercial re-use. See rights and permissions. Published by BMJ.

For numbered affiliations see end of article.

Correspondence to

Mrs Julie Labra;

julie.labra@svha.org.au

\section{ABSTRACT}

Objectives Gastrostomy decision making is a

complicated, multifaceted process for people with motor neuron disease (MND). This study explored demographic and disease-related factors that may impact on gastrostomy uptake; and reasons why people with MND accepted or declined gastrostomy, with a focus on how perceptions of swallowing and nutrition may influence decision making.

Design Prospective, cross sectional, mixed methods. Setting An Australian multidisciplinary, specialty MND Service.

Participants 33 patients were recommended gastrostomy by the treating medical specialist. 16 of 33 were invited to participate in the prospective decision making study; of whom 10 provided informed consent.

\section{Primary and secondary outcome}

measures Demographic and disease-related factors contributing to uptake are described. A stepped approach was applied to gain a comprehensive understanding of why people with MND accept or decline gastrostomy. Instruments included standardised assessments, nutrition survey and semistructured interview. Data were collected at three separate appointments, spanning a 3-week period.

Results Gastrostomy uptake was $73 \%$ following medical specialist recommendation. Participants took days, weeks or months to consider their preferences, with lengthy hospital waiting times for the procedure. Gender, site of onset and rate of disease progression were observed to contribute to uptake. Age and symptom duration did not. Integration of quantitative and qualitative data suggests that patient perceptions of swallowing and nutrition contribute to gastrostomy acceptance; however, the decision making process is heterogeneous and these factors may not be the sole or primary reasons for acceptance. Other reported factors included: reducing carer burden, improving quality of life, increasing independence, continuing participation in social outings and gaining control.

Conclusions Future research may give greater insight into how healthcare organisations can better facilitate gastrostomy decision making, to meet the needs of people living with MND. Larger, prospective, multisite studies may build on these findings to better inform clinical guidelines and minimise the impacts of delayed gastrostomy insertion.

\section{Strengths and limitations of this study}

Few studies have focused solely on gastrostomy decision making in motor neuron disease.

- None have used a mixed-methods approach, allowing both patient perspectives and clinician-reported measures to be captured, for comprehensive understanding of this complex topic.

- Integration of quantitative and qualitative data was achieved through repeated iteration process.

- The small sample size in a single clinic setting may limit generalisability of the findings; however, this provides foundation knowledge for future studies.

\section{INTRODUCTION}

Motor neuron disease (MND) is the name given to a group of progressive neurological diseases whereby motor neurones degenerate and die. Voluntary control of muscles is lost, causing difficulties with mobility, speech, swallowing and breathing. Average survival from symptom onset ranges from 20 to 48 months. ${ }^{12}$ People living with MND are faced with many challenging decisions during the course of their illness, ${ }^{3-5}$ including whether to undergo gastrostomy or not.

Gastrostomy may be suggested for longterm nutritional support. It offers a useful method for administering medication, food and fluid, to stabilise weight loss and potentially prolong survival. ${ }^{6-9}$ Reported gastrostomy uptake rates vary considerably in MND, ranging from $14 \%$ to $60 \%$ internationally, with a trend for increased usage rates over the past few decades. ${ }^{10}$ A variety of factors have been found to contribute to gastrostomy uptake, including: employment status, IQ education, executive function, perceptions and attitudes ${ }^{11}$; spirituality or religion ${ }^{11}{ }^{12}$; early positive views towards gastrostomy ${ }^{13}$; ALS Functional Rating Scale-Revised (ALSFRS-R) swallowing score, forced vital capacity (FVC) and use of non-invasive ventilation (NIV) ${ }^{14}$; pleasure associated with oral intake or ability 


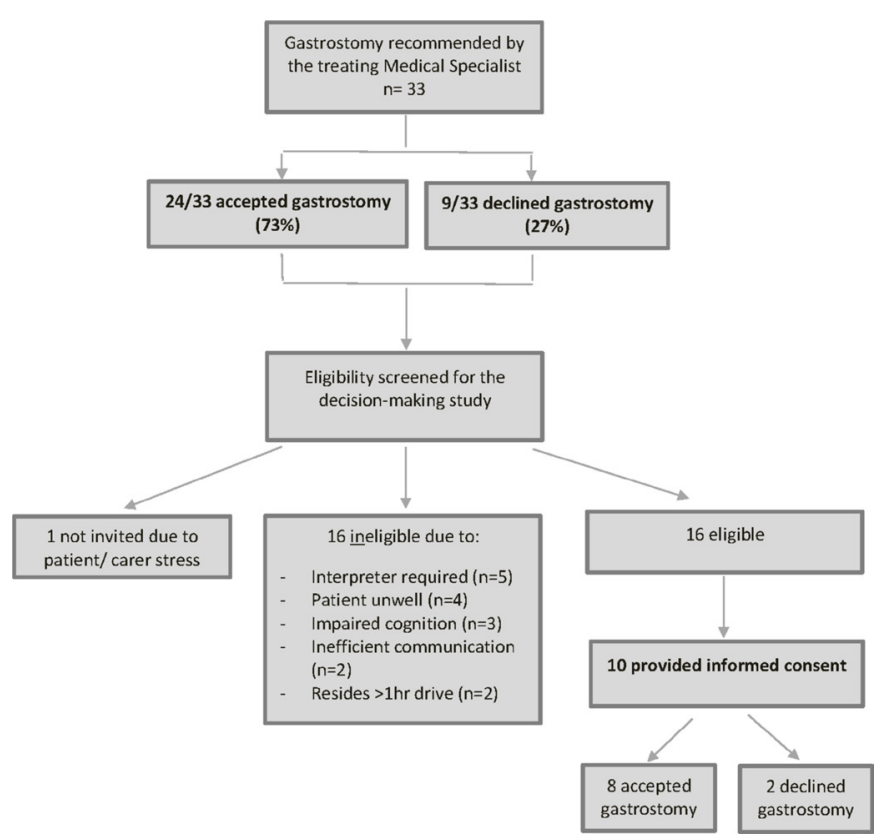

Figure 1 Participant recruitment.

to feed self ${ }^{15}$ and the use of nutritional support teams during initial gastrostomy discussion. ${ }^{16}$

Practice guidelines offer some support for clinicians regarding the timing of insertion ${ }^{78} 17$; however, most healthcare professionals (HCPs) find the issue of gastrostomy timing to be extremely challenging. ${ }^{18}$ Guidelines recommend that gastrostomy should be considered soon after symptom onset ${ }^{7}$ and offered at least annually ${ }^{8}$; swallowing and nutrition risk should be screened 3 monthly, ${ }^{8}$ with gastrostomy indicated for those with symptomatic dysphagia and associated weight loss. ${ }^{717}$ Respiratory function should also be considered, with possibly less surgical risks if gastrostomy is placed before FVC falls below $50 \%{ }^{8}{ }^{17} 19$ It has been suggested that further research is required to determine what degree of swallowing impairment, nutritional compromise and respiratory impairment indicates the need for gastrostomy. ${ }^{67}$

Before recommending gastrostomy, clinicians should be aware of each person's health status, prognosis, potential ethical issues, the expected effect on quality of life (ie, QoL) and the person's preferences. ${ }^{9}$ Proactive gastrostomy discussions are beneficial for both patients and families, ${ }^{20}$ as delayed insertion may lead to a higher rate of unplanned insertions, ${ }^{21}$ resulting in: a higher 30-day mortality rate ${ }^{21}$; increased length of hospital stay; fewer home discharges and increased healthcare costs. ${ }^{22}$ However, there is often disparity between patients' decisions and practice guidelines, even when conditions for decision making are optimal. ${ }^{23}$ Barriers to well-timed gastrostomy decisions include: patients perceiving a lack of clear advice from HCP's around the 'right time' for insertion ${ }^{24}$; patient reluctance to plan for the future ${ }^{425}$ and varying personality philosophies. ${ }^{4}$ Stavroulakis $e t a l^{26}$ also reported the following factors can influence the decision of gastrostomy insertion, and thus delay the procedure: a reluctance to give up oral feeding, a lack of understanding of the potential benefits and negative perceptions of gastrostomy tubes.

This study aimed to explore: (1) demographic and disease-related factors that may impact on gastrostomy uptake and (2) the reasons why people with MND accept or decline gastrostomy, with specific focus on how perceptions of swallowing and nutrition may influence patients' decision making.

\section{METHODS}

\section{Participants and setting}

Participants were recruited from a specialty MND Service in New South Wales (NSW), Australia, between May 2016 and February 2018. Participants attended 3-monthly, multidisciplinary, MND clinic reviews within a subacute hospital setting. Additional outpatient appointments, home visits and/or inpatient admissions (Rehabilitation or Palliative Care) were provided on an as-needed basis. The team included the following: Service Coordinator, Rehabilitation Specialist, Neurologist, Palliative Care Nurse, Allied Health, Pastoral Care and a representative from MND NSW. All respiratory investigations and gastrostomy insertions were provided by the Respiratory and Gastroenterology departments at the nearest major tertiary hospital.

\section{Recruitment procedure}

Gastrostomy need was identified during routine care, following deterioration in the patient's swallowing, nutrition or breathing. Names of patients, who had been recommended gastrostomy during a clinical discussion with the treating medical specialist (during the study period), were provided to the research team $(n=33)$. Although some patients are likely to have had prior knowledge of gastrostomy, this was the first occasion that gastrostomy referral was recommended by the medical specialist. Eligible patients were consecutively invited to participate in the decision making study, regardless of whether they had made a decision or not, to ensure that patients were captured during their decision making process (figure 1). Inclusion criteria were: sufficient English language skills to allow informed consent and optimal participation in data collection activities; ability to respond to open-ended questions using speech, writing or a communication device; sufficient cognitive ability to provide informed consent and participate in a semistructured interview (determined by a score of $\geq 25 / 30$ on the Mini-ACE) ${ }^{27}$; and residing within a 1 -hour drive from the hospital, to allow for data collection at home. Patients were not invited to participate in the decision making study if the treating team considered gastrostomy to be an unsuitable option (eg, those with poor health status or limited prognosis).

\section{Design}

A cross-sectional mixed-methods design ${ }^{28}$ was chosen as the most appropriate method to achieve the study aims 
of investigating the demographic, disease, swallow and nutritional status of participants and their perspectives on factors affecting their decision making in relation to gastrostomy. ${ }^{29-31}$ The Creswell et al best practice guidelines for mixed-methods research ${ }^{29}$ and the Sale and Brazil $^{32}$ mixed-methods reporting criteria ${ }^{32}$ informed the design and reporting of this study. Descriptive data were used to highlight differences in the demographic and disease-related characteristics for gastrostomy uptake versus declining gastrostomy.

\section{Data collection}

To explore factors impacting on gastrostomy uptake, the following demographic and disease-related data were obtained from the MND Service database: gender, age, site of onset, symptom duration (months), the rate of disease progression score (also known as $\Delta \mathrm{FS})^{33} 34$ at initial visit to the clinic and the predicted rate of decline group $^{34}$ at initial visit to the clinic. The $\Delta \mathrm{FS}$ was calculated using the following formula ${ }^{33} 34$ :

$$
\Delta F S=\frac{48-(\text { Total ALSFRS }-R \text { at initial visit })}{\text { Symptom duration at initial visit }(\text { months })}
$$

The $\Delta \mathrm{FS}$ score was then used to allocate a predicted rate of decline group, including: slow (ie, a score of $<0.47$ ), steady (ie, a score of $0.47-1.11$ ) or rapid (ie, a score of $>1.11){ }^{34}$

To capture both patient perceptions and clinicianreported measures of swallowing and nutrition, validated tools ${ }^{35-40}$ and a nutrition survey were administered. (table 1). Additionally, a semistructured interview guide (online supplementary material) explored the reasons why people with MND accept or decline gastrostomy; with specific focus on how perceptions of swallowing and nutrition may influence patients' decision making. A 3-day food record was encouraged for participants who were living at home at the time of data collection, however, as only four food records were completed, these were not included in our analysis.
The 'Perception of Nutrition Survey' (online supplementary material) and the 'SemiStructured Interview Guide' were developed for the purposes of this study, following a literature review and then further refined by the research team. The nutrition survey comprised 26 Likert scale questions. The interview guide included 16 open-ended questions targeting: participants' perception of their swallowing and nutrition; their gastrostomy decision making experience; as well as factors contributing to their decision. The guide was piloted with one MND patient and one HCP prior to study visits. No changes were suggested. Interviews were conducted by one researcher who was unknown to the participants and not involved in their care. This researcher was trained to use the interview guide by three members of the research team, during two training sessions prior to commencing study visits. Interviews were audio recorded, with member checking $^{30}$ conducted throughout the interview and on completion.

\section{Sequence}

Swallowing, nutrition and interview data were collected concurrently, at three separate appointments (30-60 min), spanning a 3-week period. This time frame was selected as minimal functional change between assessments would be expected during this short period; and also to minimise the burden on participants. The order of the assessments varied according to availability of the researchers. The appointment location was determined by participants' preferences, either: the participant's home; inpatient unit of the hospital setting or hospital outpatient appointment.

\section{Data analysis \\ Demographic and disease-related data}

Given the small sample size of this study, a descriptive report of demographic and disease-related characteristics is presented, comparing those who accepted gastrostomy with those who declined $(n=33)$.

Table 1 Instruments and procedures

\begin{tabular}{|c|c|c|c|}
\hline Purpose & Instrument & Validated? & Person administering \\
\hline Overall function rating & $\begin{array}{l}\text { Self-Reported ALS Functional Rating } \\
\text { Scale-Revised (ALSFRS-R) })^{35}\end{array}$ & Yes & Speech pathologist \\
\hline Clinician assessment of swallowing & $\begin{array}{l}\text { Mann Assessment of Swallowing Ability } \\
(\mathrm{MASA})^{36}\end{array}$ & Yes & Speech pathologist \\
\hline Participant perception of swallowing & $\begin{array}{l}\text { Swallowing-Quality of Life Scale (SWAL- } \\
\text { QoL) }\end{array}$ & Yes & Speech pathologist \\
\hline Clinician assessment of nutrition & Mini Nutritional Assessment (MNA) 3940 & Yes & Dietitian \\
\hline Participant perception of nutrition & Perception of Nutrition Survey & No & Dietitian \\
\hline
\end{tabular}




\section{Decision making data}

A stepped approach was used to gain a comprehensive and cohesive understanding of the reasons why people with MND accept or decline gastrostomy:

1. Descriptive analysis of each participants' physical function, swallowing ability and nutritional status was conducted.

2. Qualitative interviews were transcribed, with removal of any identifiable content. Transcriptions were then imported into QSR NVivo V.11 software (QSR International, Melbourne, Australia) for management and analysis by one researcher (AH). A stepwise inductive approach $^{41}$ was employed to identify emerging factors from the interviews. Participant statements on factors influencing their decision making were identified to form a framework. These factors were then matched against the participants who had identified them and grouped into categories. Four researchers reviewed the categories, factors and participant statements until consensus was reached.

3. Each participants' quantitative and qualitative datasets were merged onto the 'Main Datasheet' (online supplementary material) for convergent data analysis and triangulation. $^{28} 29$

4. A repeated iteration process was then implemented for data integration, to increase depth of understanding of this topic. Four principal investigators collaborated in three meetings, to first review each participant's results; then compare results among all participants, until consensus was reached. The MND Service Coordinator (ie, principal investigator, JL) was present at these meetings, adding contextualised information on the MND Service and clinical situation of the participants.

To maintain confidentiality, all participants were assigned an identification number to represent them in the data.

\section{Patient and public involvement.}

Patient and public involvement was achieved in the following ways. First, during investigators' (JL and NJ) clinical work, informal observations of patients with MND engaging in gastrostomy decision making and the challenges associated with this process, influenced the conceptualisation and design of this study. Second, a patient with MND trialled the semi-structured interview guide and their feedback was incorporated into the design. Finally, patient opinion, gathered through stakeholder engagement, also influenced the design and development of this study. $^{42}$

\section{RESULTS}

Comparing demographic and disease-related characteristics for those who accepted gastrostomy versus declined gastrostomy

Thirty-three medical discussions regarding gastrostomy insertion were held, either as an outpatient (24/33) or inpatient $(9 / 33)$; occurring on average 214 days after
Table 2 Demographic and disease-related characteristics for those who accepted gastrostomy versus declined gastrostomy $(n=33)$

\begin{tabular}{|c|c|c|}
\hline Characteristic & $\begin{array}{l}\text { Accepted } \\
(\mathrm{n}=24)\end{array}$ & $\begin{array}{l}\text { Declined } \\
(n=9)\end{array}$ \\
\hline Mean age (years) & 67.6 & 68.4 \\
\hline Median symptom duration (months) & 13 & 12 \\
\hline \multicolumn{3}{|l|}{ Gender } \\
\hline Female $(n=13)$ & 13 & 0 \\
\hline Male $(n=20)$ & 11 & 9 \\
\hline \multicolumn{3}{|l|}{ Site of onset } \\
\hline Bulbar $(n=14)$ & 12 & 2 \\
\hline Limb $(n=19)$ & 12 & 7 \\
\hline $\begin{array}{l}\text { Median 'Rate of Disease } \\
\text { Progression Score (ie, } \triangle F S \text { )' at initial } \\
\text { visit to the clinic }\end{array}$ & 0.88 & 2.00 \\
\hline
\end{tabular}

Predicted rate of decline group at initial visit to the clinic

\begin{tabular}{lll} 
Slow $(n=5)$ & 2 & 3 \\
Steady $(n=16)$ & 16 & 0 \\
Rapid $(n=12)$ & 6 & 6 \\
\hline
\end{tabular}

initial contact with the service (range 0-1365 days). Gender ratio included 13 females: 20 males. Mean age at the time of gastrostomy discussion was 67.3 years (range 40-84 years). Site of onset included 19 limb onset and 14 bulbar onset. Median symptom duration was 13 months (range 3-127 months). Median $\Delta \mathrm{FS}$ was 0.91 (range 0.07-8.30). Twelve participants were predicted to be 'rapid' decliners ( 7 males and 5 females); 16 were 'steady' decliners (9 males, 7 females) and 5 were 'slow' decliners (4 males, 1 female). ${ }^{34}$

Following medical discussion, 24/33 (73\%) consented to gastrostomy referral (figure 1). The median time between discussion and referral was 6 days (range 0-57 days), with nine participants taking $>1$ week to consent to referral; and three of these $>1$ month. All participants who were referred for gastrostomy, underwent percutaneous endoscopic gastrostomy (ie, PEG) insertion at a later point, ${ }^{6}$ with a median of 52 days (range 18-163 days) between referral and insertion. Table 2 compares the characteristics of those who accepted gastrostomy referral, with those who declined. Age and symptom duration appear similar in these two groups, however, there appears to be a trend towards females and those with bulbar onset accepting gastrostomy. The median rate of disease progression score at initial visit to the clinic was lower for those who accepted gastrostomy (ie, $\Delta$ FS 0.88 compared with 2.00 ). In addition, those with a predicted 'steady' rate of decline appeared more likely to accept gastrostomy, when compared with 'slow' or 'rapid' decliners, suggesting that these variables may contribute to gastrostomy uptake. 


\section{Reasons for accepting or declining gastrostomy}

Of the 33 patients who were recommended gastrostomy, 16 were excluded from the mixed methods decision making study for the following reasons: interpreter required $(n=5)$; patient unwell or in another hospital $(\mathrm{n}=4)$; impaired cognition $(\mathrm{n}=3)$; inefficient communication method $(\mathrm{n}=2)$ and residing $>1$ hour's drive away $(n=2)$. One patient was not invited to participate due to significant patient and carer stress at the time. Sixteen eligible patients were invited to participate in the mixedmethods study, of whom 10 provided informed consent (figure 1).

There was an average of 32 days between medical discussion of gastrostomy and enrolment in the decision making study (range 6-73 days). Data collection was completed between 2 and 31 days post enrolment date, with an average of 16 days to complete the three appointments. All scored $\geq 25 / 30$ on the Mini-ACE cognitive screen. Eight participants communicated by speech during the interview and one via writing. Sadly, one participant died 7 days after enrolment, prior to completing data collection.

At the time of data collection, all participants had received gastrostomy education from the multidisciplinary MND team. Five out of nine had received health literature about gastrostomy. Four had prior exposure to somebody with a gastrostomy and five had been shown a PEG device. Most discussed their decision with family (8/10); however, two participants (P3 and P8), instead made an autonomous decision.

A summary of participant characteristics for the decision making study $(\mathrm{n}=10)$ are outlined in table 3 . Merged quantitative and qualitative data can be found on the Main Datasheet (online supplementary material). Following a repeated iteration process of data analysis and integration, participant findings were grouped into those who 'declined gastrostomy' or 'accepted gastrostomy'. These results are presented as case vignettes for two reasons. First, this allowed illustration of the commonalities and differences between the members of each group. Second, case vignettes facilitated direct comparison between quantitative results and qualitative findings.

\section{Participants who declined gastrostomy}

Two of 10 participants initially declined gastrostomy and maintained this decision (P2 and P10). These participants shared similar characteristics, including: male, limbonset, disease duration $<1$ year, predicted 'rapid' decline and $>3 \mathrm{~kg}$ weight loss. They did, however, differ in their swallowing ability. P2 experienced dysphagia, requiring modified diet and fluids; whereas P10 showed no signs of dysphagia and managed a normal diet. Unfortunately, P2 died prior to interview. P10 was interviewed, giving his views on why he declined gastrostomy. P10 explained that he did not want any life-prolonging interventions, as he associated a high level of disability with a poor quality of life. He hoped to reduce the time of his illness, so as not to be a burden on his wife.

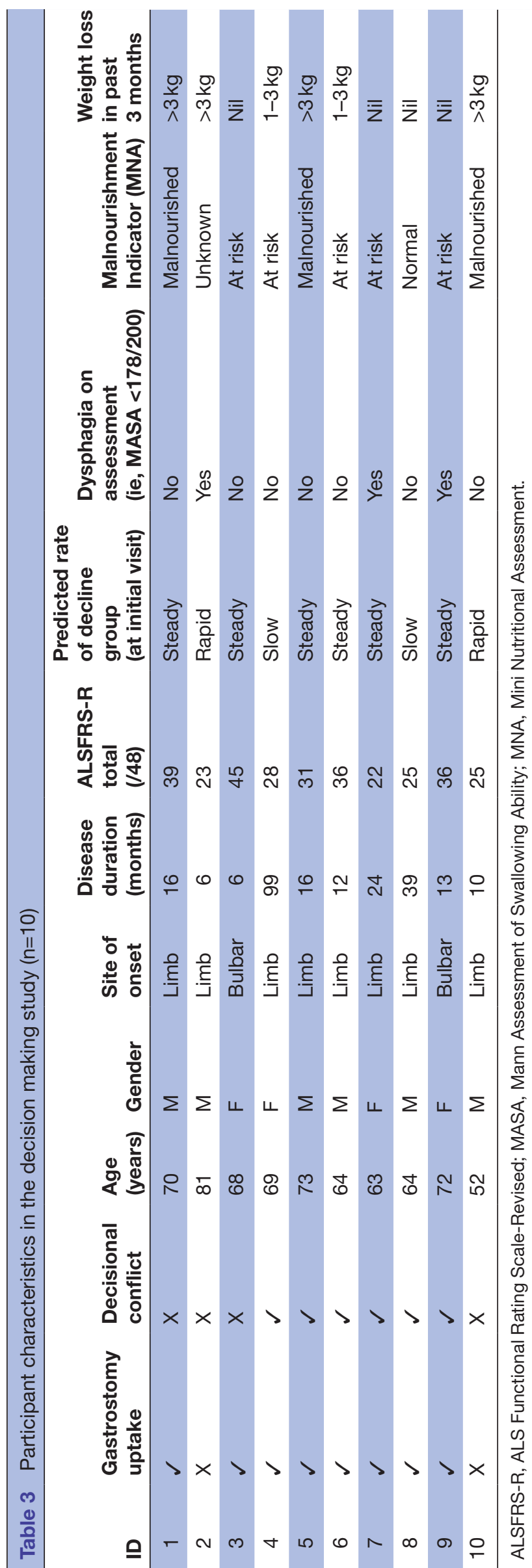


... when I really started thinking about what was going to happen and what the benefits, and pros and cons were, as to what I would get out of it, I didn't think it was worth it all......all it's going to do is maybe give me an extra month or something like that in life, in quality that I don't want and make it uncomfortable now.

Knowing what the end result is going to be, the things leading up to the end results, and trying to minimise the time for that to happen-to be in that state. I'd rather accelerate that state (as declining the PEG would lead to potentially faster deterioration) than be in that state for a few months.

P10 also wanted to be comfortable at the end-of-life and remain at home, rather than spending time in hospital to undergo gastrostomy surgery.

Yeah, plus too another-plus a hospital stay, like, I haven't got that long anyway, I don't want to spend time in hospital if I don't need to.

P10 died 10 weeks after the initial gastrostomy discussion was held.

\section{Participants who accepted gastrostomy}

The remaining eight participants chose to proceed with gastrostomy insertion. Two had their PEG inserted prior to enrolment ( 3 and 16 days prior); the remaining six after study enrolment.

Two of eight made their decision immediately following medical discussion (P1 and P3). P1 was malnourished, but swallowing was normal. He was concerned about his nutrition and potential future decline in his swallowing; however, his primary reason for gastrostomy was to reduce the burden to his wife:

I had to think about my wife because she's the one that's gotta do things for me. She's involved as much as I am.

P3 had early swallowing difficulties with some choking incidents. She ate a mostly normal diet consistency, but avoided certain foods due to dysphagia and found it harder to swallow medications. P3 was cautious whilst eating and drinking, subsequently taking longer to complete meals. She feared pneumonia, and there was risk of malnourishment with reduced appetite. Nevertheless, her weight and oral intake were stable. P3 had prior experience of someone with MND who used gastrostomy feeding and gave several reasons for immediately accepting gastrostomy:

The biggest impact would be being active, remaining active and being what they call matriarchal. I know that (PEG) is going to give me better quality of life...I will be able to stay stronger...it will make me be more independent and when I get swallowing less, I can use PEG to keep up my nutrition. I am thinking that it will help me because you can still go out....I like to go shopping with my daughter.
The remaining six participants (ie, P4, P5, P6, P7, P8, P9) all experienced decisional conflict-initially declining gastrostomy, but later changing their mind. Three of these six participants (ie, P5, P7 and P9) were observed to have dysphagia or nutritional compromise on the clinician-reported measures. These participants also reported stress and burden associated with swallowing or nutrition in the interview; yet they experienced decisional conflict and delay in making their decision for PEG. This highlights that changes in a person's swallowing or nutrition do not necessarily equate with a quick acceptance of gastrostomy. P5 had normal swallowing, but his intake was moderately reduced due to a loss of appetite and taking longer to eat. He experienced less enjoyment of eating, requiring encouragement from his family to maintain his intake. He ate two meals and drank less than 3 cups of fluid each day. P5 thought he only occasionally ate enough; but was not overly concerned about this.

P5: I'll be honest, as regards to PEG, I was very undecided. I've got a strange outlook on this, but as I've said to a few people, "I just wish it'd all end" ... I feel as I'm becoming a burden to everyone. But after talking to (MND NSW worker) ... and telling me that it's all about quality of life ... and sitting down and thinking about it, I decided to go ahead with it. But I was hesitant even right up until having it done. I was unsure but I'm not sorry now... the protein that they've been pouring into me here, it all-well, so much easier because I hate this stuff. I hate pouring it down my throat.

P7 had stable weight with no change in intake. She managed a normal diet, but avoided certain foods due to dysphagia and took longer to eat. P7 had also experienced some choking incidents, so was sometimes fearful of eating and drinking. She felt her swallowing problem was a major distraction in her life and was often frustrated by it, as it made socialising more difficult. P9 also had dysphagia, requiring modified food textures. Due to some choking incidents, P9 was cautious with eating and drinking, consequently taking longer to finish meals. Like P7, dysphagia was sometimes a cause of frustration and made socialising challenging. Each day, P9 ate three meals and drank only 3-5 cups of fluid. Despite risk of malnourishment, reduced appetite and intake, her weight was stable. P9 was not particularly concerned about increasing her intake, feeling it was mostly enough.

P9: It was a gradual change in my decision. As swallowing got worse I couldn't drink water and thickened stuff was not pleasant. So I thought to be hydrated in summer was a good idea and also taking medications would be easier through the tube. When my breathing started deteriorating and I heard that if we left it too long I might not be able to have the operation, I wanted to get on with it as quickly as possible.

P4 differed (from P5, P7 and P9) in that although her nutrition was compromised, it was not causing stress or 
burden at the current time. P4 had heard of PEG a few months prior to study enrolment, but at that time she had no bulbar involvement, her appetite was good and her weight was stable. At the time of gastrostomy recommendation, P4 did not have dysphagia, however, there was significant respiratory impairment. Constipation and breathlessness were having a negative impact on her nutrition. P4's appetite had reduced in the months prior and there was little enjoyment associated with eating; however, she felt she mostly ate enough for her needs. Sensing that her nutrition was likely to continue worsening, P4 eventually decided to accept gastrostomy. Nevertheless, her only reported reason for accepting gastrostomy was to proactively address problems associated with potentially worsening swallowing and nutrition in the future, not to address her current nutritional issues.

Interestingly, P8's primary reason for accepting gastrostomy was also to address future issues, but only issues with nutrition, not swallowing. P8 was the only participant with normal nutrition and normal swallowing at the time of data collection. Nonetheless, he did have significant respiratory impairment, so gastrostomy was recommended to ensure he was well enough to undergo the procedure.

While other participants focused on quality of life, P6 was the only participant accepting gastrostomy to make a comment regarding the potential of gastrostomy to increase survival:
P6: The idea of extending-having a surgical procedure is probably a bit intrusive but it happens, but [I] just wonder about the practicality of it-is it worth having done to extend your life for 10 weeks?

Although there were no signs of dysphagia on his swallowing assessment (ie, Mann Assessment of Swallowing Ability), P6 was fearful of choking. Body mass index was 'normal', however, P6 had lost $17 \mathrm{~kg}$ since symptom onset. He reported little interest in eating and meals took longer to finish, however, P6 felt he mostly ate enough for his needs.

A summary of factors contributing to gastrostomy decision making, identified in the semi structured interviews $(\mathrm{n}=9)$ are provided in table 4 .

Overall, these results highlight that gastrostomy decision making in MND is a heterogeneous process, varying from person to person; and irrespective of the presence of swallowing impairment or nutritional compromise. In addition, there may be disparity between patient perceptions' of their swallowing or nutrition and clinicianreported measures.

\section{DISCUSSION}

Gastrostomy uptake and decision making is a complicated, multifaceted process for people living with MND. This prospective study is the first of its kind, utilising

Table 4 Factors contributing to gastrostomy decision making, identified in the semistructured interviews $(n=9)$

Participant number

(A=accepted gastrostomy; $\mathrm{D}=$ declined gastrostomy)

Contributing factor

\begin{tabular}{lllllllll}
\hline 1 & 3 & 4 & 5 & 6 & 7 & 8 & 9 & 10
\end{tabular}

Improve/maintain healthy body, nutrition and hydration
Reduce carer burden


a convergent mixed-methods approach ${ }^{28}$ to explore demographic and disease-related factors contributing to gastrostomy uptake in MND; and the reasons why patients accept or decline gastrostomy. Results provide further insights to: empower HCPs; better inform larger-scale studies, clinical guidelines and development of shared decision making aids; and finally, to improve the decision making experience for people living with MND.

Integration of quantitative and qualitative data suggests a heterogeneous decision making process for people living with MND, irrespective of the presence of swallowing impairment or nutritional compromise. At times there may also be some disparity between patient perceptions' of their swallowing or nutrition and results from clinician-reported measures; an important consideration for clinicians when approaching gastrostomy discussions. While patient perceptions of swallowing and nutrition do contribute to gastrostomy acceptance,${ }^{26}$ these factors may not be the sole or primary reasons for accepting gastrostomy. Other reasons such as reducing carer burden, ${ }^{24}$ improving QoL, ${ }^{24}$ increasing independence, continuing participation in social outings and gaining $\mathrm{control}^{24}$ were reported. Reasons for declining gastrostomy focused on avoiding life-prolonging measures to limit carer burden, as well as avoiding hospital admission for the procedure. The gastrostomy uptake rate in our study was higher than previously reported rates from an Australian MND clinic-based study, ${ }^{16}$ yet similar to the rate reported by Greenaway $e t a l^{24}$ This is the first study to highlight rate of disease progression as a potential variable contributing to gastrostomy uptake. All participants with a predicted 'steady' rate of decline accepted gastrostomy, whereas those with predicted 'slow' or 'rapid' decline appeared less likely to accept. Gender may also contribute to gastrostomy uptake, with women appearing more likely to accept gastrostomy than men, this being similar to previous findings. ${ }^{43}$ Differences in site of onset were also observed; however, age and symptom duration appeared similar among both groups.

The timing of the decision varied according to patients' priorities and concerns. While most patients eventually consented to gastrostomy referral, this decision could take an extended period of time, ${ }^{26}$ regardless of the presence of swallowing impairment or nutritional compromise. The median time between medical discussion and gastrostomy referral in our study was $<1$ week. Even so, this gap was $>1$ month in almost $10 \%$ of the cohort, with the longest taking 57 days. Additionally, there were delays between referral and gastrostomy insertion. These findings help to quantify the decision making and referral periods, highlighting a combination of decisional conflict for some patients, as well as lengthy hospital waiting times to undergo the procedure at this site. With this in mind, early gastrostomy discussions that are: person- centred, exploratory, regularly reviewed post initial introduction, and allow for the fact that patients may take days, weeks or months to consider their decision; may improve the patient's decision making experience and their health outcomes. Decision making models and aids that support proactive interdisciplinary and participative approaches to care discussions, may be helpful in these circumstances, to promote informed decisions that are consistent with personal values and beliefs. ${ }^{1842445}$ These results also highlight important considerations for gastrostomy services, when aiming for a more responsive service delivery model, enabling rapid access to insertion.

While gastrostomy decision making has been explored in other conditions ${ }^{444647}$ and in conjunction with NIV decision making in MND, ${ }^{418} 24$ few studies have focused solely on gastrostomy decision making in MND, ${ }^{26} 48$ and none have used a mixed-methods approach for comprehensive understanding of this complex topic. Largerscale, mixed-methods comparisons across a variety of sites would assist with identifying how different clinical models or decision making aids might impact on gastrostomy uptake and decision making. Additionally, future studies investigating how clinicians decide patients' suitability for gastrostomy, and the frequency of reviewing patients' decisions would add new insights.

This study was limited by the small sample size and use of a single site, thus incorporating selection bias and limiting generalisation of findings. The first author (JL) acted as both clinician and researcher in this study. The advantage of this participant observer role was added familiarity with the study population and clinical processes, ${ }^{49}$ however, this relationship may have introduced observer bias, as this clinician was also involved in data collection and analysis. To minimise this bias in the data collection phase, an independent researcher was used to conduct the interviews. The interviews included only one person who declined gastrostomy, reflecting the uptake rate in this study and the proportion of decliners included in previous studies. ${ }^{1624}$ Even so, further research exploring the reasons for declining gastrostomy is required. Due to small sample size and the nature of this study, we were unable to perform statistical analyses and draw strong conclusions from the data. Nevertheless, the results provide important foundational considerations for future larger-scale studies. Future longitudinal studies investigating the relationship between gastrostomy uptake and: demographic, disease-related factors, swallowing, nutrition and respiratory markers would allow for more detailed comparisons; and better inform clinicians about the timing of gastrostomy recommendation.

\section{CONCLUSION}

The Australian healthcare system may be unable to facilitate well-timed gastrostomy insertion. Future research may give greater insight into how healthcare organisations can better facilitate gastrostomy decision making, as well as rapid access to insertion, in order to meet the needs of people living with MND. Larger, prospective, multisite studies that provide further insights into both quantitative and qualitative reasons for gastrostomy acceptance 
and decline are required, to better inform clinical guidelines and minimise the impacts of delayed insertion.

\section{Author affiliations}

${ }^{1}$ Motor Neurone Disease Service, St Joseph's Hospital, Auburn, New South Wales, Australia

${ }^{2}$ Australian Institute of Health Service Management, University of Tasmania, Sydney, New South Wales, Australia

${ }^{3}$ Speech Pathology, University of Technology Sydney, Sydney, New South Wales, Australia

${ }^{4}$ Speech Pathology Department, St Joseph's Hospital, Auburn, New South Wales, Australia

${ }^{5}$ Sydney School of Health Sciences, Faculty of Medicine and Health, The University of Sydney, Sydney, New South Wales, Australia

${ }^{6}$ Research and Education Network, Westmead Hospital, Western Sydney Local Health District, Westmead, New South Wales, Australia

Twitter Anne Hogden @annehogden, Emma Power @dr_epower and Victoria M Flood @FloodVicki

Acknowledgements Linda Clarke; Amal Owaimrin; Jeanette Sprott; Olivia Vun; Aqdas Habib.

Contributors JL: study conception and design; acquisition, analysis and interpretation of data; drafting the paper and final approval for publication. AH: study design; data analysis and interpretation; critical review of the paper and final approval for publication. EP: study design; data analysis and interpretation; critical review of the paper and final approval for publication. NJ: study conception and design; data collection; critical review of the paper; and final approval for publication. VF: study design; data analysis and interpretation; critical review of the paper and final approval for publication.

Funding This work was supported by a St Vincent's Clinic Foundation 'Multidisciplinary Patient-Focused Research Grant'.

Competing interests None declared.

Patient consent for publication Not required.

Ethics approval This project was granted ethics approval by St Vincent's Health Australia (SVHA) Human Research Ethics Committee (HREC/15/SVH/428).

Provenance and peer review Not commissioned; externally peer reviewed.

Data availability statement All data relevant to the study are included in the article or uploaded as supplementary information.

Open access This is an open access article distributed in accordance with the Creative Commons Attribution Non Commercial (CC BY-NC 4.0) license, which permits others to distribute, remix, adapt, build upon this work non-commercially, and license their derivative works on different terms, provided the original work is properly cited, appropriate credit is given, any changes made indicated, and the use is non-commercial. See: http://creativecommons.org/licenses/by-nc/4.0/.

\section{ORCID iDs}

Julie Labra http://orcid.org/0000-0001-8273-016X

Anne Hogden http://orcid.org/0000-0002-4317-7960

\section{REFERENCES}

1 Chiò A, Logroscino G, Hardiman O, et al. Prognostic factors in ALS: a critical review. Amyotroph Lateral Scler 2009;10:310-23.

2 Traxinger K, Kelly C, Johnson BA, et al. Prognosis and epidemiology of amyotrophic lateral sclerosis: analysis of a clinic population, 1997-2011. Neurol: Clin Prac 2013;3:313-20.

3 Foley G, Timonen V, Hardiman O. Acceptance and decision making in amyotrophic lateral sclerosis from a life-course perspective. Qual Health Res 2014;24:67-77.

4 Hogden A, Greenfield D, Nugus P, et al. What influences patient decision-making in amyotrophic lateral sclerosis multidisciplinary care? A study of patient perspectives. Patient Prefer Adherence 2012;6:829-38.

5 Hogden A, Greenfield D, Nugus P, et al. Engaging patients in decision-making in amyotrophic lateral sclerosis multidisciplinary care: the views of health professionals. Patient Prefer Adherence 2012;6:691-701.
6 Progas study group. Gastrostomy in patients with amyotrophic lateral sclerosis (ProGas): a prospective cohort study. Lancet Neurol 2015;14:702-9.

7 Miller RG, Jackson CE, Kasarskis EJ, et al. Practice parameter update: the care of the patient with amyotrophic lateral sclerosis: drug, nutritional, and respiratory therapies (an evidence-based review): report of the Quality Standards Subcommittee of the American Academy of Neurology. Neurol 2009;73:1218-26.

8 Miller RG, Brooks BR, Swain-Eng RJ, et al. Quality improvement in neurology: amyotrophic lateral sclerosis quality measures: report of the quality measurement and reporting Subcommittee of the American Academy of Neurology. Neurol 2013;81:2136-40.

9 Löser C, Aschl G, Hébuterne X, et al. ESPEN guidelines on artificial enteral nutrition--percutaneous endoscopic gastrostomy (PEG). Clin Nutr 2005;24:848-61.

10 Katzberg HD, Benatar M. Enteral tube feeding for amyotrophic lateral sclerosis/motor neuron disease (review). The Cochrane Lib 2011.

11 Martin NH, Landau S, Janssen A, et al. Psychological as well as illness factors influence acceptance of non-invasive ventilation (NIV) and gastrostomy in amyotrophic lateral sclerosis (ALS): a prospective population study. Amyotroph Lateral Scler Frontotemporal Degener 2014;15:376-87.

12 Murphy PL, Albert SM, Weber CM, et al. Impact of spirituality and religiousness on outcomes in patients with ALS. Neurol 2000;55:1581-4.

13 Albert SM, Murphy PL, Del Bene ML, et al. A prospective study of preferences and actual treatment choices in ALS. Neurol 1999;53:278.

14 Jackson-Tarlton CS, Benstead TJ, Doucette S, et al. Correlating factors in the recommendation of feeding tubes in the nutritional management of amyotrophic lateral sclerosis. Amyotroph Lateral Scler Frontotemporal Degener 2016;17:515-21.

15 Johnson J, Leigh PN, Shaw CE, et al. Eating-derived Pleasure in amyotrophic lateral sclerosis as a predictor of non-oral feeding. Amyotroph Lateral Scler 2012;13:555-9.

16 Zhang L, Sanders L, Fraser R. Nutritional support teams increase percutaneous endoscopic gastrostomy uptake in motor neuron disease. WJG 2012;18:6461-7.

17 Andersen PM, Abrahams S, Borasio GD, et al. EFNS guidelines on the clinical management of amyotrophic lateral sclerosis (MALS)-revised report of an EFNS task force. Eur J Neurol 2012;19:360-75.

18 Martin NH, Lawrence V, Murray J, et al. Decision making about gastrostomy and noninvasive ventilation in amyotrophic lateral sclerosis. Qual Health Res 2016;26:1366-81.

19 Mathus-Vliegen LMH, Louwerse LS, Merkus MP, et al. Percutaneous endoscopic gastrostomy in patients with amyotrophic lateral sclerosis and impaired pulmonary function. Gastrointest Endosc 1994;40:463-9.

20 Seeber AA, Hijdra A, Vermeulen M, et al. Discussions about treatment restrictions in chronic neurologic diseases: a structured review. Neurol 2012;78:590-7.

21 Tsou A, Long J, McCluskey L, et al. Predictors of 30-day mortality after gastrostomy in ALS. Neurol 2012;78.

22 Tsou AY, Karlawish J, McCluskey L, et al. Predictors of emergent feeding tubes and tracheostomies in ALS. Amyotroph Lateral Scler 2012;13:318-25.

23 Munroe CA, Sirdofsky MD, Kuru T, et al. End-Of-Life decision making in 42 patients with amyotrophic lateral sclerosis. Respir Care 2007:52:996-9.

24 Greenaway LP, Martin NH, Lawrence V, et al. Accepting or declining non-invasive ventilation or gastrostomy in amyotrophic lateral sclerosis: patients' perspectives. J Neurol 2015;262:1002-13.

25 Hugel H, Grundy N, Rigby S, et al. How does current care practice influence the experience of a new diagnosis of motor neuron disease? A qualitative study of current guidelines-based practice. Amyotroph Lateral Scler 2006;7:161-6.

26 Stavroulakis T, Baird WO, Baxter SK, et al. Factors influencing decision-making in relation to timing of gastrostomy insertion in patients with motor neurone disease. BMJ Support Palliat Care 2014;4:57-63.

27 Hsieh S, McGrory S, Leslie F, et al. The Mini-Addenbrooke's cognitive examination: a new assessment tool for dementia. Dement Geriatr Cogn Disord 2015;39:1-11.

28 Rapport F, Hogden A, Faris M, et al. Qualitative research in healthcare - modern methods, clear translation: a White Paper. Sydney, Australia: Australian Institute of Health Innovation, Macquarie University, 2018.

29 Creswell J, Klassen A, Clark P V, et al. For the office of behavioural and social sciences research. best practices for mixed methods research in the health sciences. National Institutes of health, 2011. Available: https://obssr.od.nih.gov/wp-content/uploads/2016/02/ 
Best_Practices_for_Mixed_Methods_Research.pdf [Accessed Oct 2018].

30 Creswell J. Research design: qualitative, quantitative, and mixed methods approaches. 4th edn. Thousand Oaks, California: SAGE publications Inc, 2014

31 Wisdom JP, Cavaleri MA, Onwuegbuzie AJ, et al. Methodological reporting in qualitative, quantitative, and mixed methods health services research articles. Health Serv Res 2012;47:721-45.

32 Sale JEM, Brazil K. A strategy to identify critical appraisal criteria for primary mixed-method studies. Qual Quant 2004;38:351-65.

33 Kimura F, Fujimura C, Ishida S, et al. Progression rate of ALSFRS-R at time of diagnosis predicts survival time in ALS. Neurology 2006;66:265-7.

34 Labra J, Menon P, Byth K, et al. Rate of disease progression: a prognostic biomarker in ALS. J Neurol Neurosurg Psychiatry 2016;87:628-32.

35 Montes J, Levy G, Albert S, et al. Development and evaluation of a self-administered version of the ALSFRS-R. Neurol 2006;67:1294-6.

36 González-Fernández M, Sein MT, Palmer JB. Clinical experience using the Mann assessment of swallowing ability for identification of patients at risk for aspiration in a mixed-disease population. Am J Speech Lang Pathol 2011;20:331-6.

37 Crary MA, Mann GDC, Groher ME, et al. Initial psychometric assessment of a functional oral intake scale for dysphagia in stroke patients. Arch Phys Med Rehabil 2005;86:1516-20.

38 McHorney CA, Robbins J, Lomax K, et al. The SWAL-QOL and SWAL-CARE outcomes tool for oropharyngeal dysphagia in adults: III. documentation of reliability and validity. Dysphagia 2002:17:97-114.

39 Guigoz Y. The Mini Nutritional Assessment (MNA) review of the literature--What does it tell us? J Nutr Health Aging 2006;10:466-87.
40 Vellas B, Villars H, Abellan G, et al. Overview of the MNA--Its history and challenges. J Nutr Health Aging 2006;10:456-65.

41 Thomas DR. A general inductive approach for analyzing qualitative evaluation data. Am J Eval June 2006;27:237-46.

42 Hogden A, Greenfield D, Caga J, et al. Development of patient decision support tools for motor neuron disease using stakeholder consultation: a study protocol. BMJ Open 2016;6:e010532.

43 Forbes RB, Colville S, Swingler RJ, et al. Frequency, timing and outcome of gastrostomy tubes for amyotrophic lateral sclerosis/ motor neurone disease--a record linkage study from the Scottish Motor Neurone Disease Register. J Neurol 2004;251:813-7.

44 Brotherton A, Abbott J. Clinical decision making and the provision of information in PEG feeding: an exploration of patients and their carers' perceptions. J Hum Nutr Diet 2009;22:302-9.

45 Mitchell SL, Tetroe J, O'Connor AM. A decision aid for long-term tube feeding in cognitively impaired older persons. J Am Geriatr Soc 2001;49:313-6.

46 Vesey S, Leslie P, Exley C. A pilot study exploring the factors that influence the decision to have PEG feeding in patients with progressive conditions. Dysphagia 2008;23:310-6.

47 Van Rosendaal GM, Verhoef MJ, Kinsella TD. How are decisions made about the use of percutaneous endoscopic gastrostomy for long-term nutritional support? Am J Gastroenterol 1999;94:3225-8.

48 Stavroulakis T, Baird WO, Baxter SK, et al. The impact of gastrostomy in motor neurone disease: challenges and benefits from a patient and carer perspective. BMJ Support Palliat Care 2016;6:52-9.

49 Johnson JC, Avenarius C, Weatherford J. The active participantobserver: applying social role analysis to participant observation. Field methods 2006;18:111-34. 